\title{
Approach to chest wall masses: Analysis of a single-center outcomes
}

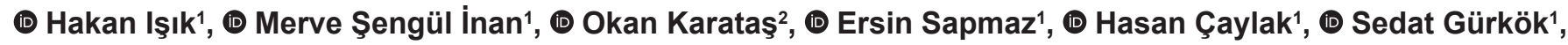 \\ (1) Onur Genç ${ }^{1}$, (1) Alper Gözübüyük ${ }^{1}$
}

1 University of Health Sciences Turkey, Gülhane Training and Research Hospital, Clinic of Thoracic Surgery, Ankara, Turkey

${ }^{2}$ Ataturk State Hospital, Clinic of Thoracic Surgery, Sinop, Turkey

Date submitted:

20.08.2020

Date accepted:

25.12.2020

Online publication date: 15.06.2021

\section{Corresponding Author:}

Hakan Işık, M.D., University of Health Sciences Turkey, Gülhane Training and Research Hospital, Clinic of Thoracic Surgery, Ankara, Turkey

ORCID:

orcid.org/0000-0002-7602-4434

Keywords: Chest wall, reconstruction, primary tumor, metastatic tumor, resection

\begin{abstract}
Aims: The chest wall has a heterogeneous structure consisting of bone, cartilage, and soft tissue. Due to its complexity, many pathologies may present as chest wall masses. The present study aimed to analyze the data of patients with a chest wall mass, who were admitted to a tertiary center.
\end{abstract}

Methods: We retrospectively evaluated the medical records of patients with a chest wall mass, who were admitted between January 2003 and December 2019. The data related to age, gender, chief complaints on admission, tumor localization, requirement of surgical treatment, length of hospital stay, histopathological diagnosis, recurrence, morbidities and mortality were recorded.

Results: The total sample included 185 patients [mean age (range): 37.6 years (12 to 88), male gender: 144 (77.8\%)]. The mean length of hospitalization was 6.62 days (1-35). The most common complaints on admission were a palpable mass $(n=60,32.4 \%)$, pain $(n=59,31.9 \%)$, and pain and a palpable mass $(n=36,19.4 \%)$. Surgery was required in $166(89.8 \%)$ patients. More than one surgery was performed in 8 (4.8\%) patients. There were $118(71 \%)$ benign and 48 (29\%) malignant histopathologic results. The most common primary chest wall malignancies were chondrosarcoma and Ewing sarcoma.

Conclusions: The majority of patients with a chest wall mass underwent surgery in this 16-year dataset. Chondrosarcoma and Ewing sarcoma were the most common primary malignancies. While most were benign tumors, a secondary intervention was required in a small percentage of patients.

\section{Introduction}

The chest wall has a heterogeneity that includes bone, cartilage, and soft tissues. Therefore, a patient with a chest wall mass can have different etiological causes. While benign lesions are the most common in their etiology, most of the malignant lesions are formed by metastatic lesions. Primary chest wall malignancies are rare and constitute $5 \%$ of thoracic malignancies (1).

The distinction of benign and malign chest wall masses is important for determining the surgical approach (2). Wide resections are performed to fulfill oncological principles and to obtain a clean surgical border in the resection of malignant masses. Proper reconstruction of the defect in the chest wall after these wide resections is important. Although chest wall resections are relatively easy surgeries to perform, reconstruction surgeries are much more difficult and complex procedures where the personal factors of the patient come to the fore. Traditional techniques, such as the use of prolene mesh (PM) and metal bars, are the most frequently used methods in reconstruction. The use of complex implants that are individualized and produced with a 3D printer stands out as a good alternative to classical methods $(3,4)$. In the present study, we aimed to evaluate of the 16-year surgical experience of a tertiary hospital thoracic surgery clinic in chest wall masses. 


\section{Methods}

Electronic medical records and patient files of inpatients and outpatients admitted between January 2003 and December 2019 were reviewed. A total of 200 patients with chest wall masses were identified, and 185 (92.5\%) of them were included in the study. Age, gender, complaints on admission, tumor localization, the requirement for surgery, length of hospital stay, histopathologic diagnosis, recurrence, morbidities and mortality data were recorded. This study was approved by the Institutional Ethics Committee of Gülhane Training and Research Hospital (approval date: June 5, 2018, approval number: 18/164). Written informed consent was provided from all patients.

Preoperative radiologic examination findings were evaluated to record the localization, size, invasion of neurovascular structures, and distant metastases. The most common imaging technique was computed tomography of the chest. Moreover, magnetic resonance imaging, ultrasonography, and scintigraphy examinations were performed for indications, such as the evaluation of the size and depth of soft tissue tumors, determination of soft tissue invasion in bone-derived tumors, investigation of brain metastasis, and for cancer staging purposes before the positron emission tomography (PET) scan. Data of PET scans to screen distant organ metastasis were available since 2006 .

\section{Statistical Analysis}

The Statistical Package for the Social Sciences, version 25 (Inc., Chicago, IL, USA) was used for the statistical analysis. Descriptive and categorical variables of 185 patients in the study were expressed as mean, number and percentage as measure of central tendency.

\section{Results}

A total of 7,604 registries were examined and 200 patients with chest wall mass diagnosis were identified. Patients with a chest wall invasion and metastases of lung cancer were excluded $(n=15)$. Six of these patients had a chest wall mass due to lung cancer metastases and nine had a T3 tumor that invaded the chest wall. Primary chest wall tumor $(n=39)$ and chest wall metastases of cancers other than lung cancer were included in the study $(n=9)$. Thus, the final analysis included the records of 185patients.

The gender distribution of 185 patients was shown [mean age (range): $37.6 \pm 1.19$ years (12 to 88$)$, male gender: $144(77.8 \%)$ ]. The mean length of hospital stay was $6.62 \pm 6.49$ days (1-35). Among the most common complaints on admission, a palpable mass in $60(32.4 \%)$ patients, pain in $59(31.9 \%)$ patients, and pain and palpable mass in $36(19.4 \%)$ were the most common ones. Twenty patients (10.8\%) were asymptomatic and they were referred to the clinic upon the incidental detection of lesions in the chest wall during examinations performed for other reasons. In seven (3.7\%) patients, chest wall lesions were identified during their routine check-up after diagnosis and treatment of other organ malignancies. Table 1 shows the distribution of patients by complaints.

Surgery was performed on 166 (89.7\%) patients and 19 $(10.3 \%)$ patients did not undergo surgery. Eleven of those patients who did not undergo a surgical procedure were followedup due to clinical and radiological findings. The preliminary diagnoses of these patients were lipoma and callus formation of old fractures. The remaining eight patients were indicated for operation after radiological and clinical evaluation; however, surgery was not performed because the patients did not accept the procedure. The most common preliminary diagnosis in this group was elastofibroma dorsi.

Concerning the preoperative diagnostic procedures in 166 patients, $48(28.9 \%)$ patients had fine-needle aspiration biopsy and tru-cut biopsy. While this procedure was performed for diagnosis in $43(25.9 \%)$ patients, it was detected that the final diagnosis was made by excisional biopsy in four $(2.4 \%)$ patients and by incisional biopsy in one $(0.6 \%)$ patient.

Eight patients $(4.8 \%)$ underwent multiple surgical interventions. Three of these were due to desmoid tumors and one was due to local recurrence of fibrous dysplasia. One intervention was a wide resection required for a safe surgical margin due to the millimetric proximity of the tumor to the surgical border in routine pathological examination with a diagnosis of pleomorphic sarcoma. Two interventions were due to lung metastases identified in routine controls performed after primary chest wall sarcoma resection. One intervention was performed for revision in the early period due to flail chest resulting from insufficient chest wall reconstruction.

The majority of patients who underwent surgical treatment consisted of patients with benign chest wall tumors ( $\mathrm{n}=118$ benign, $\mathrm{n}=48$ malignant). Of the malignant lesions, $39(81.2 \%)$ were primary chest wall tumors and nine (18.8\%) were metastatic tumors. The distribution of these lesions is summarized in Table 2.

The patients who underwent wide resection were discussed at the multidisciplinary council, which included a plastic surgeon, and a final decision was made for surgery and the reconstruction

\begin{tabular}{|lll|}
\hline Table 1. The complaints of patients on admission $(\mathbf{n = 1 8 5})$ \\
\hline $\begin{array}{l}\text { Complaint at the time of } \\
\text { admission }\end{array}$ & $\begin{array}{l}\text { Number of } \\
\text { patients }(\mathbf{n})\end{array}$ & $\begin{array}{l}\text { Percentage } \\
(\%)\end{array}$ \\
\hline Palpable mass & 60 & 32.4 \\
\hline Pain & 59 & 31.9 \\
\hline Palpable mass and pain & 36 & 19.4 \\
\hline Asymptomatic & 20 & 10.8 \\
\hline Tumor follow-up patient & 7 & 3.8 \\
\hline Dyspnea & 2 & 1.1 \\
\hline Cough & 1 & 0.6 \\
\hline
\end{tabular}




\begin{tabular}{|c|c|c|c|}
\hline Malign & $n=48$ & Benign & $n=118$ \\
\hline Metastasis & 9 & Lipoma & 24 \\
\hline Chondrosarcoma & 8 & Fibrous dysplasia & 19 \\
\hline Ewing sarcoma & 8 & $\begin{array}{l}\text { Enchondroma/ } \\
\text { osteochondroma }\end{array}$ & 18 \\
\hline $\begin{array}{l}\text { Multiple } \\
\text { myeloma }\end{array}$ & 4 & Elastofibroma dorsi & 12 \\
\hline $\begin{array}{l}\text { Malignant fibrous } \\
\text { histiocytoma }\end{array}$ & 3 & $\begin{array}{l}\text { Old fracture healing } \\
\text { (regenerative tissue) }\end{array}$ & 11 \\
\hline $\begin{array}{l}\text { Solitary } \\
\text { plasmacytoma }\end{array}$ & 3 & Desmoid Tumor & 9 \\
\hline Fibrosarcoma & 3 & Hemangioma & 7 \\
\hline Osteosarcoma & 2 & Schwannoma & 2 \\
\hline $\begin{array}{l}\text { Pleomorphic } \\
\text { sarcoma }\end{array}$ & 2 & Lymphangioma & 2 \\
\hline $\begin{array}{l}\text { Malignant nerve } \\
\text { sheath tumor }\end{array}$ & 2 & Nodular fasci & 2 \\
\hline $\begin{array}{l}\text { Malign } \\
\text { mesenchymal } \\
\text { tumor }\end{array}$ & 2 & $\begin{array}{l}\text { Langerhans cell } \\
\text { histiocytosis }\end{array}$ & 2 \\
\hline $\begin{array}{l}\text { Synovial } \\
\text { sarcoma }\end{array}$ & 1 & Tuberculosis & 2 \\
\hline \multirow[t]{7}{*}{ PEComa } & 1 & Foreign body reaction & 2 \\
\hline & & $\begin{array}{l}\text { Inflammatory } \\
\text { myofibroblastic tumor }\end{array}$ & 1 \\
\hline & & Hydatid cyst & 1 \\
\hline & & Simple bone cyst & 1 \\
\hline & & Eosinophilic granuloma & 1 \\
\hline & & Thyroglossal duct cyst & 1 \\
\hline & & Paranganglioma & 1 \\
\hline
\end{tabular}

strategy was determined. In 20 operations performed on 17 $(10.2 \%)$ patients, prosthetic material was used for chest wall reconstruction after wide resection. Materials used were 10 PM, 5 PM + methyl methacrylate (MMA), 2 PM + titanium bar, 1 PTFE mesh + titanium bar, 2 custom-made titanium implants in three-dimensional printer. Pectoralis major muscle flap in one patient, latissimus dorsi muscle flap in one patient, and rectus abdominis muscle flap in one patient were used by the plastic surgeon for soft tissue repair.

In one patient, reconstruction was performed with titanium bar and PM after the resection of a $27 \times 22 \times 18 \mathrm{~cm}$ chondrosarcoma originating from the anterior chest wall (Figure 1). The patient could not be extubated due to a flail chest which developed due to insufficient reconstruction. Later, the patient was re-evaluated, and an effective reconstruction was achieved with the custommade titanium implant produced with a three-dimensional printer (Figure 2), and the patient was extubated.

No preoperative death occurred; however, seven (4.2\%) patients developed major complications. One patient was

treated with debridement and long-term anti-biotherapy due to postoperative wound infection. Intraoperative massive hemorrhage developed in two patients who underwent hemangioma surgery and wide chest wall resection. The hemorrhage control performed with the appropriate method and blood replacement were completed without morbidity and mortality in both surgeries. Flail chest developed after wide chest wall resection and reconstruction in two patients. One of these patients was treated with the support of a mechanical ventilator without the need for additional surgery, while the other patient was re-operated on and stabilization was achieved (Figures 1, 2). Pulmonary embolism was seen in two patients in the postoperative period and both were successfully treated with medical treatment.

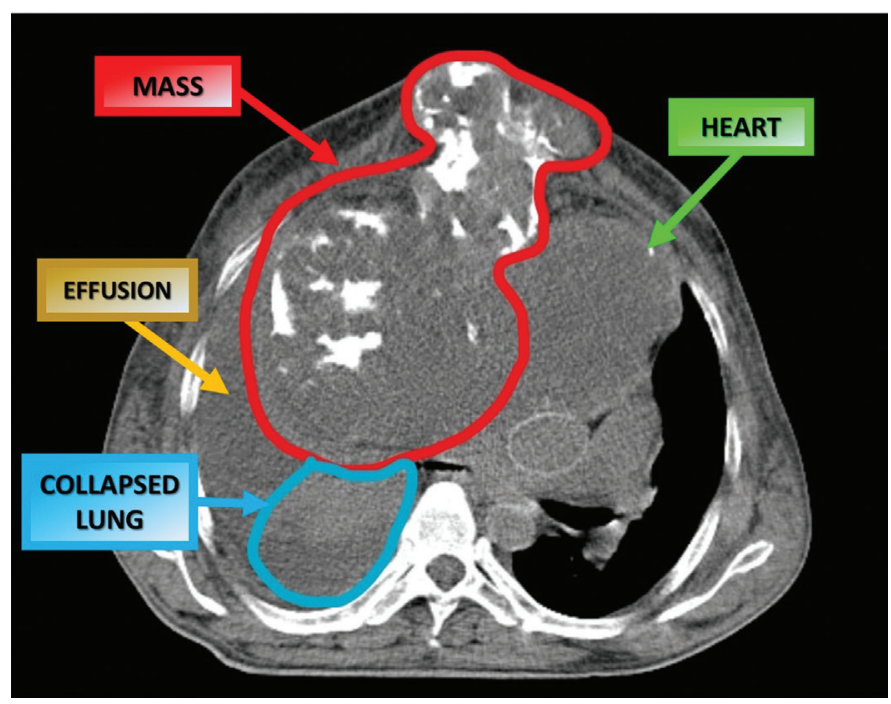

Figure 1. Red: Giant mass originated from the anterior chest wall (chondrosarcoma). Green: Heart deviated to the left hemithorax. Yellow: pleural effusion. Blue: Right lung with total collapse due to compression of the mass

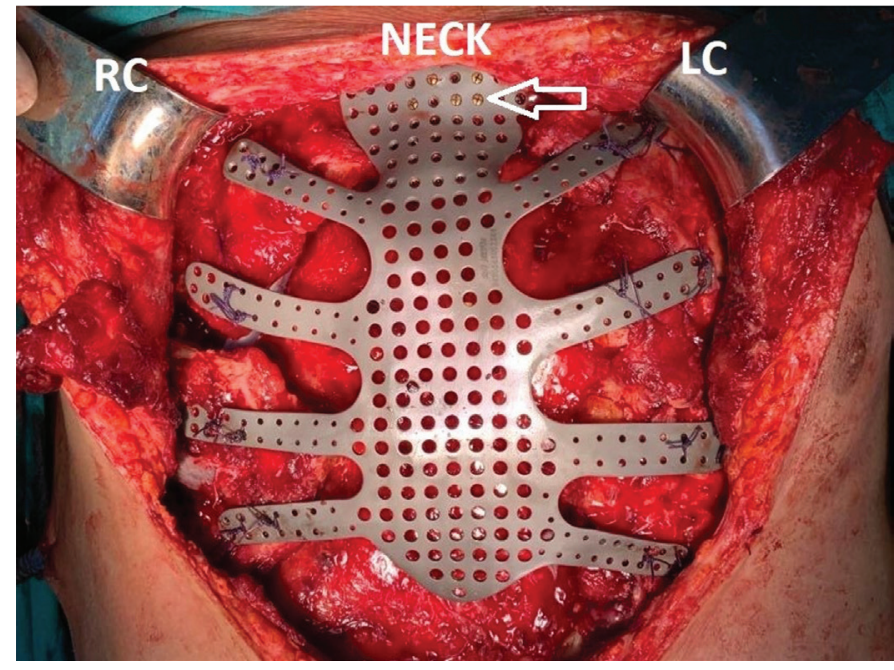

Figure 2. Chest wall reconstruction applied with custom-made titanium implant produced on a 3D printer (RC: Right clavicula, LC: Left clavicula, Arrow: Titanium screw) 


\section{Discussion}

The existing literature suggests that approximately half of the primary chest wall masses are malignant (5). In the present study, we revealed 48 malignancies against 118 benign lesions. Thus, in contrast to the literature, benign cases were significantly more common in our study. The chest wall contains many different tissues; a significant number of the complaints at the time of admission was for pain and the presence of a palpable mass. The presence of pain has been associated with poor prognosis (6). At least one of these two complaints was present in 155 of the patients (83.7\%).

Benign-malignant differentiation of the lesion may not be possible with anamnesis, physical examination, and radiological imaging. However, the most decisive stage in the clinicians' determination of treatment strategies in approaching chest wall lesions is to make this histopathological distinction. Knowing the nature of a lesion, benign or malignant, facilitates the management of the process. Fine-needle aspiration biopsy may be used in most lesions. Due to its size, anatomical relation, and nature, the need for incisional or excisional biopsy may arise. Incorrect histopathological diagnosis may lead to incomplete resection and relapse.

Despite advanced chemotherapy and radiotherapy regimens, surgery is still essential for the treatment of many chest wall lesions. Total excision should always be targeted particularly to prevent relapse. However, sometimes complete excision of the lesion requires a wide chest wall resection. A compatible, effective, and cosmetically acceptable reconstruction method should be determined for such patients. Choosing the wrong method may result in the development of respiratory failure by disrupting the pulmonary functions in the patient. Besides, the reconstruction material to be used should have high tissue compatibility and should not cause a local infection. For this purpose, in addition to classical methods such as PM, MM, and titanium bar, we use custom-made titanium implants produced in 3D printer, which is a new technology. The method for the management of reconstruction of wide defects depends mainly on the experience of the clinic. For choosing the right material, each patient should be evaluated individually, and a decision should be made accordingly (7).

Malignant tumors of the chest wall are mostly of bone origin and the 5 -year survival time is below $60 \%$. The most common primary malignant tumor is chondrosarcoma (8). According to data of our series, the most common malignancies in the chest wall were metastases and the primary malignant tumors were chondrosarcoma and Ewing sarcoma. In the treatment of chondrosarcoma, the only definite cure reported is complete surgery. Wide resection should not be avoided to prevent relapse $(9,10)$. In 3 of the 8 chondrosarcoma patients in the series, a wide resection above $10 \mathrm{~cm}$ requiring reconstruction was performed. Upon the development of postoperative flail chest in one patient, a special titanium implant was produced with the 3D laser printer technology and placed in the second surgery. Therefore, both respiratory functions could be preserved, and an unacceptable aesthetic appearance could be prevented.

The authors noted that Ewing sarcoma and condrosarcoma are the most common primary chest wall malignancies. Unlike the literature, we noticed that the number of Ewing sarcomas was equal to that of chondrosarcoma. Ewing sarcoma is a very rare primary chest wall malignancy, but it is noteworthy that it was equal in number with chondrosarcoma in our series. Multiple myeloma ( $\mathrm{MM}$ ) is in the second place after chondrosarcoma and Ewing sarcoma. The mean age of four patients with rib-induced $\mathrm{MM}$ in the series was 66.2 years and the first symptom was pain. Despite radiotherapy and chemotherapy after total resection, 5-year survival in $\mathrm{MM}$ has been reported to be below $10 \%$. The mean follow-up period of the patients was 26.2 months, and 2 patients passed away $(11,12)$.

In two of the patients, a high-grade bone tumor, osteosarcoma, was present. In one of these patients, osteosarcoma developed in the fifth rib after radiotherapy for breast cancer. After a wide chest wall resection, the defect was reconstructed using a titanium bridge and PM (Figure 3). The development of osteosarcoma in rib, whose primary malignancy is very rare, was noteworthy. The authors consider that with the increase of RT practice, more radiation-induced osteosarcoma originating from the chest wall may be encountered in the future (13). The most effective treatment method for malignant tumors is surgery. The entire involved costa with the upper and lower costa should be partially resected with the surrounding soft tissue with a safe area of at least 4-6 cm (14).

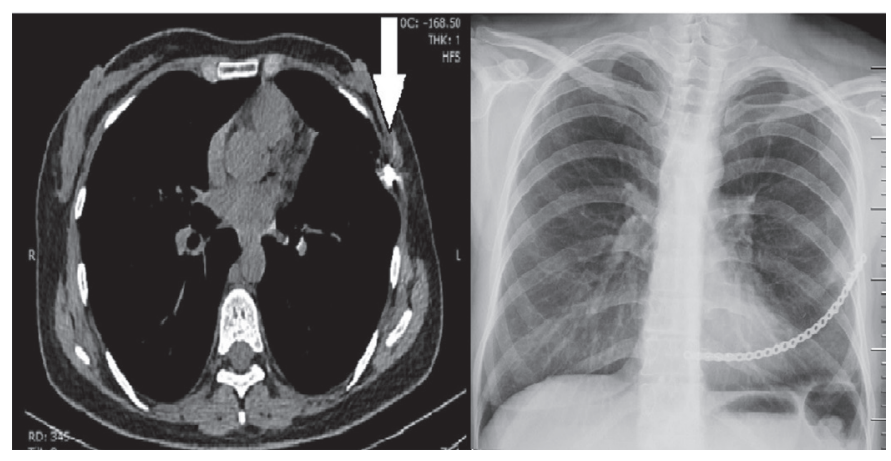

Figure 3. Preoperative view of the mass in the left fifth rib and postoperative chest $\mathrm{X}$-ray showing titanium bridge

The benign chest wall lesions that were most frequently detected in the patients were lipoma, fibrous dysplasia, and osteochondroma. Ribs are a very rare localization for osteochondromas, the most common benign tumor of bone. In the study, 11 patients who underwent surgery had osteochondroma and seven patients had chondroma. Partial sternum resection was performed in one patient since the 
chondroma originated from the sternum. It is very important to clinically differentiate these bone and cartilage tumors from chondrosarcoma. Although the chondrosarcoma transformation of osteochondromas is reported as less than $1 \%$, it still must be kept in mind $(15,16)$.

Fibrous dysplasia accounts for $1 \%$ of primary bone tumors. Although the optimal treatment strategy is still uncertain, there is a surgical indication of pain and conservative treatment in unresponsive patients (17). In the study, fibrous dysplasia was detected in 19 patients. Only one of these patients was asymptomatic, and the rest were admitted to the hospital with pain. The tumor was localized in the costa of patients, and none had concomitant endocrinopathy. For this reason, surgical treatment was preferred. In one patient, partial vertebral resection was performed in addition to the rib resection. While recurrence was seen only in one patient in this group, no mortality was encountered during an average follow-up of 47 months. These results show that surgery is an effective method in fibrous dysplasia.

Desmoid tumor is a pathology that does not metastasize but has a locally aggressive structure. Although desmoid tumor has a benign histologic profile, some authors categorize it as malign, due to its local aggressive growth pattern. Surgical treatment was applied again in three of nine patients who underwent resection with the diagnosis of local recurrence. This high recurrence rate demonstrates the need for a wide safe range in desmoid tumor surgery such as malignant lesions. The most accurate approach in preventing local recurrence is to provide a negative surgical margin $(18,19)$.

Lipoma and Elastofibroma dorsi are common soft tissue lesions of the chest wall. Elastofibroma dorsi occurs more frequently in females and mostly over the age of 55 years (20). There were a total of $12(7.2 \%)$ patients, including three males and nine females, who underwent operation due to the diagnosis. In the study, the mean age was calculated as 46.9 years, younger than studies in the literature.

The study has limitations as it is a single-center retrospective study; thus, a selection bias could not be neglected. Also, the small sample size of the study population limits the generalizability of the findings.

\section{Conclusion}

The majority of patients with a chest wall mass underwent surgery in this 16-year dataset. The majority of tumors were in benign types. The most common malignant type chest wall was mass metastasis, whereas chondrosarcoma and Ewing sarcoma were the most common primary malignancies. Unlike the literature, Ewing sarcomas were more common in our series. A secondary intervention was required in a small percentage of patients with a chest wall mass.

\section{Ethics}

Ethics Committee Approval: This study was approved by the Institutional Ethics Committee of Gülhane Training and Research Hospital (approval date: June 5, 2018, approval number: 18/164).

Informed Consent: Written informed consent was provided from all patients.

Peer-review: Externally peer-reviewed.

\section{Authorship Contributions}

Surgical and Medical Practices: H.Ç., S.G., O.G., A.G., Concept: E.S., S.G., Design: H.I., M.Ş.İ., E.S., Data Collection or Processing: H.I., M.Ş.I., Analysis or Interpretation: H.Ç., S.G., Literature Search: H.I., M.Ş.İ., O.K., Writing: H.I., M.Ş.İ., O.G.

Conflict of Interest: No conflict of interest was declared by the authors.

Financial Disclosure: The authors declared that this study received no financial support.

\section{References}

1. Lin GQ, Li YQ, Huang LJ, Luo FY, Jiang HH, Luo WJ. Chest wall tumors: diagnosis, treatment, and reconstruction. Exp Ther Med. 2015;9:1807-1812.

2. Özuslu BA, Genç O, Gürkök S, Balkanlı K. Chest wall tumors. Asian Cardiovasc Thorac Ann.1998;6:212-215.

3. Gonfiotti A, Santinia PF, Campanacci D, et al. Malignant primary chest-wall tumors: techniques of reconstruction and survival. Eur J Cardiothorac Surg. 2010;38:39-45.

4. Wang B, Mei X, Liu W, Yu F. Chest wall reconstruction with 3-dimensional custom-made carbon fiber ribs. J Thorac Cardiovasc Surg. 2018;156:177-179.

5. Nicastri DG, Swati GN, Williams EE, Flores RM. Chest wall tumors. In: Shields, Locicero J, Feins RH, Colson YL, Rocco G (eds), General thoracic surgery 8th edition. Philadelphia: Lippincott Williams \& Wilkins, 2019;13311355.

6. Anderson BO, Burt ME. Chest wall neoplasms and their management. Ann Thorac Surg. 1994;58:1774-1781.

7. Sanna S, Brandolini J, Pardolesi A, et al. Materials and techniques in chest wall reconstruction: a review. J Vis Surg. 2017;3:95.

8. David E, Marshall MB. Review of chest wall tumors: a diagnostic, therapeutic, and reconstructive challenge. Semin Plast Surg. 2011;25:16-24.

9. Seo WS, Remotti F, Lee FY. Chondrosarcoma of Bone. In: Schwartz HS ed, Orthopaedic knowledge update: musculoskeletal tumors 2. Rosemont, IL: American Academy of Orthopaedic Surgeons. 2007;185-195.

10. Gelderblom H, Hogendoorn PC, Dijkstra SD, et al. The clinical approach towards chondrosarcoma. Oncologist. 2008;13:320-329. 
11. Alshati MH, Kumar R, Kannan S. Dyspnea, Massive effusion and lytic rib lesion as initial presentation of multiple myeloma in a young man. Can Respir J. 2013;20:253-255.

12. Sharma D, Rawat V, Yadav R. A rare case of multiple myeloma presenting as lytic lesion of the rib. J Clin Diagn Res. 2016:10:20-21.

13. Chapelier AR, Bacha EA, de Montpreville VT, et al. Radical resection of radiation induced sarcoma of the chest wall: report of 15 cases. Ann Thorac Surg. 1997;63:214-219.

14. Bostancı K, Göğüs duvarı tümörleri ve cerrahi tedavisi. In: Yüksel M, Balcı AE (editörler), Göğüs cerrahisi kırmızı kitap 2. baskı. İstanbul: Nobel Tıp Yayınevi. 2015;571-580.

15. Kadu V, Saindane A, Goghate N, Goghate N. Osteochondroma of the Rib: a rare radiological appearance. J Orthop Case Rep. 2015;5:62-64.
16. Yıldız YH. Benign cartilage tumors: enchondroma and osteochondroma. TOTBID Dergisi. 2013;12:517-525.

17. Traibi A, El Oueriachi F, El Hammoumi M, Al Bouzidi A, el Kabiri $\mathrm{H}$. Monostotic fibrous dysplasia of the ribs. Interact Cardiovasc Thorac Surg. 2012;14:41-43.

18. Papagelopoulos P, Mavrogenis A, Mitsiokapa E, et al. Current trends in the management of extra-abdominal desmoid tumors. World J Surg Oncol. 2006;4:21-28.

19. Escobar C, Munker R, Thomas JO, et al. Update on desmoid tumors. Ann Oncol. 2012;23:562-569.

20. Go PH, Meadows MC, Marie B, Chamberlain RS. Elastofibromadorsi: a soft tissue masquerade. Int $\mathrm{J}$ Shoulder Surg. 2010;4:97-101. 